\title{
EDS, HRTEM/STEM and X-ray absorption spectroscopy studies of Co-substituted maghemite nanoparticles
}

\author{
D. Carta, ${ }^{1, *}$ A. Corrias, ${ }^{1}$ A. Falqui, ${ }^{2}$ R. Brescia, ${ }^{2}$ E. Fantechi, ${ }^{3}$ F. Pineider ${ }^{3,4}$, C. Sangregorio ${ }^{3,5}$
}

${ }^{1}$ Dipartimento di Scienze Chimiche e Geologiche and INSTM, Università di Cagliari, S.P. Monserrato-Sestu Km 0.700, I-09042 Monserrato, Cagliari, Italy

${ }^{2}$ Istituto Italiano di Tecnologia, I.I.T. - Via Morego 30, 16163 Genoa, Italy.

${ }^{3}$ INSTM and Department of Chemistry "U. Schiff”, Università di Firenze, via della Lastruccia 3, Sesto Fiorentino, I-50019 Firenze, Italy.

${ }^{4}$ C.N.R. - I.S.T.M. clo Dipartimento di Scienze Chimiche, Università di Padova and INSTM, Via Marzolo 1, I-35131, Padova, Italy

${ }^{5}$ C.N.R. - I.S.T.M. via C. Golgi 19, I-20133 Milano, Italy.

* To whom correspondence should be addressed. E-mail: $\underline{\text { dcarta@unica.it }}$

\begin{abstract}
A detailed study of the composition and structure of approximately $5 \mathrm{~nm}$ diameter monodisperse Co-doped maghemite nanoparticles with systematically varying composition has been carried out by Electron Microscopy techniques, HRTEM/STEM and Energy Dispersive Spectrometry (EDS), and by X-ray absorption spectroscopy (XAS) at the Fe and Co K-edges, analyzing both the Extended X-ray absorption fine structure (EXAFS) and the X-ray absorption near edge structure (XANES) regions. The latter techniques in particular, allow us to determine the degree of inversion in the spinel structure of the nanoparticles. The nanoparticles are made by single crystals with the composition corresponding to the Fe/Co ratio used in the synthesis. The degree of inversion is quite similar for all samples and close to the value found in a pure cobalt ferrite bulk sample.
\end{abstract}




\section{Introduction}

Nanoparticles of transition metal spinel ferrites have been the subject of increasing interest due to their magnetic and catalytic properties, different from those of bulk materials. These unique properties make make them ideal materials for the fabrication of nanodevices to be employed in a wide variety of applications ranging from data storage to electronics, energy conversion and biomedicine. ${ }^{1-4}$ Ferrites have the general formula $\mathrm{AB}_{2} \mathrm{O}_{4}$, where $\mathrm{A}$ and $\mathrm{B}$ denote divalent and trivalent metal ions, respectively. They normally adopt the typical cubic spinel structure, with a unit cell containing 32 oxygen atoms in a close packed cubic arrangement with 24 cations occupying 8 of the 64 available tetrahedral sites and 16 of the 32 available octahedral sites. ${ }^{5}$ In a normal spinel structure, the 8 tetrahedral sites are occupied by bivalent cations and the 16 octahedral sites are occupied by trivalent cations. On the other hand, in the inverse spinel structure 8 tetrahedral sites are occupied by trivalent cations, 8 octahedral sites are occupied by trivalent cations and 8 octahedral sites are occupied by bivalent cations. ${ }^{6}$ If the bivalent cations are present on both tetrahedral and octahedral sites the spinel is partially inverted. The structural formula for a generic spinel compound $\mathrm{MFe}_{2} \mathrm{O}_{4}$ can be written as: ${ }^{7}$

$\left[\mathrm{M}_{1-\mathrm{i}} \mathrm{Fe}_{\mathrm{i}}\right]^{\mathrm{A}}\left[\mathrm{M}_{\mathrm{i}} \mathrm{Fe}_{(2-\mathrm{i})}\right]^{\mathrm{B}} \mathrm{O}_{4}$

where the numbers in brackets represent the average occupancy of A-sites (tetrahedral) and B-sites (octahedral) and $i$ is the inversion parameter (the fraction of divalent ions $\mathrm{M}$ occupying octahedral cavities). For a normal spinel $i=0$ and for an inverted spinel $i=1$. Moreover, ferrites can easily accommodate vacancies, as in maghemite, $\gamma-\mathrm{Fe}_{2} \mathrm{O}_{3}$, a thermodynamically metastable form of $\mathrm{Fe}$ (III) oxide, whose unit cell formula can be written in the form $\mathrm{Fe}_{2.67} \Xi_{0.33} \mathrm{O}_{4}$ (where $\Xi$ stands for vacancies) which shows that the $\gamma-\mathrm{Fe}_{2} \mathrm{O}_{3}$ structure is strictly related to that of the inverse spinel magnetite $\mathrm{Fe}_{3} \mathrm{O}_{4}$.

It has been found that most mixed ferrites, such as cobalt- and manganese ferrites, are partially inverted, ${ }^{8}$ and that in nanoparticles their inversion degree can significantly differ depending on the adopted synthetic conditions $;{ }^{9}$ moreover, some authors suggested that changes in the particle size 
can influence magnetic properties due to changes in cation distribution. ${ }^{10}$ Therefore, physical properties of ferrites can be easily tuned over wide ranges by replacing, either completely or partially, the divalent or trivalent metal ions. In particular, an increase of magnetic anisotropy is observed going from magnetite to cobalt ferrite by replacement of $\mathrm{Fe}^{2+}$ with the more anisotropic $\mathrm{Co}^{2+}$ cation. Due to the enhanced magnetic properties, $\mathrm{CoFe}_{2} \mathrm{O}_{4}$ has been proposed as a possible alternative to iron oxides, i.e. magnetite and maghemite, for biomedical applications, as contrast agent for Magnetic Resonance Imaging (MRI) and heat mediator for Magnetic Fluid Hyperthermia $(\mathrm{MFH}) .{ }^{11}$

In the present work, we have investigated a family of ca. $5 \mathrm{~nm}$ diameter monodisperse Co-doped maghemite nanoparticles where the composition was systematically varied from maghemite to stoichiometric cobalt ferrite. We decided to focus on doped maghemite rather than on mixed valence magnetite since the oxidation of $\mathrm{Fe}^{2+}$ ion represents a variable which can be difficult to control. All the nanoparticles were synthesized by thermal decomposition of metal acetylacetonates, which allowed us to obtain monodisperse nanoparticles with high crystallinity. The investigation of the magnetic and magneto-optical properties of these nanoparticles has previously shown a peculiar trend with the cobalt content, the main feature being the large increase of the saturation magnetization and the anomalous dependence of magnetic anisotropy which reaches its maximum values for intermediate compositions. ${ }^{12}$ To properly correlate the modifications to the magnetic and magneto-optical properties of the nanoparticles induced by $\mathrm{Co}^{2+}$ replacement in the spinel lattice, a detailed analysis on the composition and on the structure of the nanoparticles was carried out by Electron Microscopy techniques, HRTEM/STEM and Energy Dispersive Spectrometry (EDS), and by X-ray absorption spectroscopy (XAS) at the Fe and Co K-edges, analyzing both the Extended Xray absorption fine structure (EXAFS) and the X-ray absorption near edge structure (XANES) regions.

In particular, spatially resolved EDS via STEM allows to determine both mean and single particle chemical composition, with the further aim to check the nanoparticle compositional 
homogeneity. On the other hand, the crystalline structure of the single nanoparticles can be investigated by HRTEM. Moreover, EXAFS and XANES have already shown to be very powerful tools for the structural study of metal oxides, ${ }^{13}$ and ferrite nanoparticles. ${ }^{14-16}$ They are ideal probes for studying multicomponent materials being element specific and sensitive to the local structure. EXAFS gives information about bond distances and coordination numbers of shells surrounding the absorbing atom; XANES gives information on oxidation state and site-symmetry of the absorbing atom. In particular, EXAFS has been recently found a useful tool to determine the cation distribution in ferrospinels, since it allows one to study separately and independently the environment around the absorbing ions. ${ }^{17-19} \mathrm{~A}$ variety of other probes has been used to provide information on cation distribution such as X-ray and neutron diffraction and Mössbauer spectroscopy. ${ }^{20}$ However, the usefulness of XRD is limited by the similar scattering factors of Co and $\mathrm{Fe}$ and by the small size of the nanoparticles that broadens the XRD peaks. Mössbauer spectroscopy is effective in determining the environment of $\mathrm{Fe}$ ions but does not provide information on the Co cations. ${ }^{21}$ Therefore, in this work, we have used XANES to accurately determine the oxidation state of the two cations and EXAFS in order to determine the cation distribution between the octahedral and tetrahedral sites with varying the cobalt content, over the whole range of Co content.

\section{Experimental Section}

\subsection{Sample Preparation}

The details of the synthesis have been reported in ref. 12. Briefly, the synthesis was carried out under inert atmosphere using commercially available reagents. Absolute ethanol (EtOH) and hexane (99\%) were used as received. Benzyl ether (99\%), 1,2-hexadecanediol (HDD) (97\%), oleic acid (90\%), oleylamine (70\%), cobalt(II) acetylacetonate (97\%) were purchased from Aldrich Chemical 
Co., and iron(III) acetylacetonate (99 \%) from Strem Chemicals, Inc. All chemicals were used as received.

In a typical synthesis, $\mathrm{Fe}(\mathrm{acac})_{3}$ and $\mathrm{Co}(\mathrm{acac})_{2}$ (in various proportions, 1 mmol total), 1,2hexadecandiol $(0.517 \mathrm{~g}, 2 \mathrm{mmol})$, acid oleic $(1.3 \mathrm{ml}, 4 \mathrm{mmol})$ and oleylamine $(1.4 \mathrm{ml}, 4 \mathrm{mmol})$ were mixed and magnetically stirred under a flow of nitrogen in benzyl ether $(50 \mathrm{ml})$. The mixture was heated to reflux (ca. $270-280^{\circ} \mathrm{C}$ ) and kept at this temperature for 15 min under a blanket of nitrogen and vigorous stirring. The black-brown mixture was cooled to room temperature by removing the heat source. Under ambient conditions, EtOH $(50 \mathrm{ml})$ was added to the mixture, causing the precipitation of a black material which was separated via centrifugation $(5000 \mathrm{rpm}, 10$ min). The black product was dispersed by sonication in EtOH several times and then centrifuged (5000 rpm, $10 \mathrm{~min}$ ) and dried. The product could be readily dispersed in hexane.

In the following the samples will be labelled as $\mathbf{C o F e} z z$, where $z z$ denotes the cobalt content, $z z$ being equal to $x^{*} 100, x$ being the atomic fraction of $\mathrm{Co}$ for the $\mathrm{Co}_{\mathrm{x}} \mathrm{Fe}_{(8 / 3-2 \mathrm{x} / 3)} \mathrm{O}_{4}$ formula unit in cobalt doped maghemite, as obtained from ICP-AES measurements, ${ }^{12}$ which are reported in Table I.

\subsection{HRTEM/STEM/EDS}

In order to perform the Electron Microscopy analysis, a drop of suspension of each sample was deposited and dried on a carbon-coated copper grid prior to observation. The analysis was carried out using a Jeol JEM 2200FS Transmission Electron Microscope (TEM), equipped with a Field Emission Gun, working at an acceleration voltage of $200 \mathrm{kV}$ and designed for High Resolution (HRTEM) imaging with a CEOS aberration corrector for the objective lens. Its ultimate point resolution in HRTEM mode is $1.0 \AA$ A. The same microscope was also used in Scanning TEM (STEM) mode with a spot of $0.7 \mathrm{~nm}$ in size and images acquired using a High Angle Annular Dark Field (HAADF) detector. EDS X-ray spectra were acquired using a $\mathrm{Si}(\mathrm{Li})$ Jeol detector from selected areas of the HAADF images with continuous drift correction. 


\subsection{X-ray absorption data collection (XANES and EXAFS)}

XAS experiments were performed at the ELETTRA synchrotron radiation facility (Trieste, Italy) on the 11.1 (XAFS) beamline. Spectra were recorded using a Si (111) monochromator in transmission mode at room temperature at the iron and cobalt K-edges for each sample. Three ion chambers were used to measure the incident, transmitted and reference beam intensities, respectively. $5 \mu \mathrm{m} \mathrm{Fe}$ and Co foils were placed between the second and third ion chambers so that the absorption spectrum of the foil was recorded simultaneously, for energy scale calibration. Energy of the first inflection point for $\mathrm{Fe}$ and $\mathrm{Co}$ foils were taken as 7112 and $7709 \mathrm{eV}$, respectively. Samples with a suitable and highly uniform optical thickness were prepared from powders diluted in polyvinylpyrrolidone (PVP) to a final concentration in the range $10-25 \% \mathrm{w} / \mathrm{w}$ and pressed as pellets.

\subsubsection{XANES data analysis}

The XANES spectra were processed in the usual way to obtain normalized absorbance. ${ }^{22}$ XANES at the K-edge involves the excitation of a 1s photoelectron into low-lying empty states at the central atom with p-type symmetry. The K-edge XANES spectra in transition metals has a gradually sloping main absorption edge, with a pronounced step on the low energy side, a rounded main absorption edge peak, and approximately constant intensity following the edge. In contrast, transition metal oxides typically exhibit a sharply rising main absorption edge, with main absorption edge peak(s) of high intensity, and a notable drop in intensity after the main absorption edge peak. In addition, oxides may show a small pre-edge peak if the excited atom site has a lack of centrosymmetry. In both metals and oxides, oscillations in intensity occurring up to approximately $30 \mathrm{eV}$ beyond the absorption edge are due to strong multiple-scattering or shape resonance around the excited atom site. The XANES spectra have been analysed using the "fingerprint" method, by comparing spectra from samples with those from reference compounds. 


\subsubsection{EXAFS data analysis}

The program Viper was used to sum the data, identify the beginning of the absorption edge, $E_{o}$, fit pre and post edge backgrounds, $\mu t_{\text {pre }}$ and $\mu t_{\text {post }}$ respectively, and hence to obtain the normalised absorbance $\chi=\left(\mu \mathrm{t}-\mu \mathrm{t}_{\mathrm{post}}\right) /\left(\mu \mathrm{t}_{\text {post }}-\mu \mathrm{t}_{\mathrm{pre}}\right)$ as a function of the modulus of the photoelectron wavevector $k .{ }^{23}$ The modular package DL_EXCURV,${ }^{24}$ based on the EXCURV98 code, was used in the final stage of data processing to model the experimental $\chi(k)$ in order to extract structural information. Fast curved wave theory was used, ${ }^{25}$ where

$\chi(k)=\Sigma_{\mathrm{i}} \mathrm{S}_{0}^{2}(k)\left(N_{\mathrm{i}} / k R_{\mathrm{i}}^{2}\right)\left|f_{\mathrm{i}}(k, R)\right| \sin \left(2 k R_{\mathrm{i}}+2 \delta(k)+\varphi_{\mathrm{i}}(k, R)\right) \exp \left(-2 \sigma_{\mathrm{i}}^{2} k^{2}\right) \exp \left(-2 R_{\mathrm{i}} / \lambda(k)\right)$

and $R_{i}, N_{i}$, and $2 \sigma_{1}^{2}$ are the distance, coordination number, and Debye-Waller term (static and thermal disorder) for the $i$ th shell of neighbouring atoms. The additional parameters in eq. 1 are the effective curved wave backscattering amplitude $f\left(k, R_{i}\right)$ of the scatterer, the phase shift due to the absorbing atom potential $2 \delta(k)$, the phase shift due to the scatterer $\varphi_{1}(k, R)$, and the inelastic mean free path of the photoelectron $\lambda(k)$. Equation 1 is valid for single scattering of the photoelectron. The fitting was carried out in $k$ space using the range $2.5-12 \AA^{-1}$, where $12 \AA^{-1}$ is the highest accessible value at the Fe K-edge due to the presence of Co K-edge. The same $k$ range was used at the Co edge in order to achieve similar resolution.

Fourier Transform (FT) of EXAFS data corrected for phase-shift shows peaks corresponding to local atom correlations. The positions of the peaks $(R)$ correspond to distances between the central and the backscatterer atoms while the amplitudes are related to the coordination number $(N)$ and to the static and thermal disorder $(\sigma)$ of the atoms around the absorber.

Theoretical parameters, $\left|f_{\mathrm{i}}\left(k, R_{i}\right)\right|, \varphi_{i}\left(k, R_{i}\right), \delta(k)$, and $\lambda(k)$, were calculated using the von Barth potential for ground states, the Hedin-Lundquist exchange potential for excited states, ${ }^{26}$ and the relaxed approximation for the core-hole. ${ }^{27}$ In DL_EXCURV the $k$-independent parameter AFAC 
takes the place of $S_{0}(k)^{2}$ in eq. 1. AFAC was determined to be 0.9 from fitting to the reference samples. The parameter $\mathrm{EF}$, which is a correction to $E_{0}$, was allowed to vary in all fitting procedures. The structural parameters were obtained by nonlinear least squares fitting in $k$-space with a $k^{3}$ weighting of experimental EXAFS spectra to emphasize the high-energy part of the spectrum. The errors in the fit parameters were obtained from the $95 \%$ confidence level, as calculated in EXCURV98. The number of fitted parameters was always less than the number of statistically independent data points, as estimated in the standard way.

The quality of the fit can be judged from the normalized sum of residuals

$\mathrm{R}$-factor $=\Sigma_{\mathrm{n}}\left|k_{n}{ }^{3} \chi_{\operatorname{expt}}\left(k_{n}\right)-k_{n}{ }^{3} \chi_{\mathrm{fit}}\left(k_{n}\right)\right| /\left|\Sigma_{\mathrm{n}} k_{n}{ }^{3} \chi_{\text {expt }}\left(k_{n}\right)\right| \times 100$

Reasonable EXAFS fits of single shells typically have values of R-factor around $20 \%$. However, when the fit is performed on the total EXAFS spectra, higher values of R-factor can still correspond to good fits especially if the fit is not extended to peaks at high $R$.

\section{Results}

\subsection{EDS and HRTEM}

HAADF STEM imaging mode provides a fast method to image all the investigated samples. Since the contrast in HAADF STEM is only due to both the thickness and the mean atomic number of the specimen, even very small and poorly crystallized nanoparticles can be imaged. Figure 1 (a)(c) shows the STEM HAADF images of large areas of three of the samples: CoFe10, CoFe66 and $\mathrm{CoFe} 94$, i.e. the sample with the lowest cobalt doping and the two samples with the highest cobalt doping. They show that the CoFe10 sample is constituted by a double population of nanoparticles: the first one contains nanoparticles with size in the range between 5 and $8 \mathrm{~nm}$, while the second one contains nanoparticles with size between 2 and $3 \mathrm{~nm}$. The nanoparticles in the other two samples have a single population with similar size distribution $(7-11 \mathrm{~nm})$. 
EDS spectra allow the determination of the chemical composition of the samples and, in particular, for the present samples the relative quantification of iron $(\mathrm{Fe})$ and cobalt $(\mathrm{Co})$ within each particle and also as an average among many particles. To this end, the relevant X-ray energy range is between $6.0 \mathrm{keV}$ and $7.5 \mathrm{keV}$, where three contributions are present: the $\mathrm{Fe} \mathrm{K}_{\alpha}$ peak, centered at $6.398 \mathrm{keV}$ and the $\mathrm{Co} \mathrm{K}_{\alpha}$ peak, centered at $6.924 \mathrm{keV}$, respectively, the latter superposing with the $\mathrm{Fe} \mathrm{K}_{\beta}$ peak at $7.057 \mathrm{keV}$. The spectra can be fitted, after removal of a constant low background, with three Gaussians, centred at each mentioned energy. The areas under the $\mathrm{K}_{\alpha}$ peaks of $\mathrm{Fe}$ and $\mathrm{Co}, I_{\mathrm{Fe}}$ and $I_{\mathrm{Co}}$, are calculated from the parameters of the fitted gaussian curves. Following the Cliff-Lorimer method, ${ }^{28}$ considered as a good approximation for both thin films and small particles, the atomic concentration ratio between two elements $i$ and $j,\left(C_{i} / C_{j}\right)$ can be related to the ratio between the corresponding peak areas, $I_{i} / \mathrm{I}_{j}$, via a multiplicative constant, i.e. the CliffLorimer factor $\left(k_{i-j, K}\right)$, multiplied by atomic weight ratio $\left(A_{i} / A_{j}\right)$ of the elements. The Cliff-Lorimer factor, $k_{i-j, K}$, depends on the electron beam energy used, $200 \mathrm{keV}$, on each specific pair of elements and on the spectral line series used, in our case K. All is summed up in the following equation:

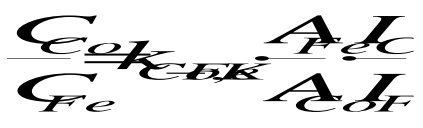

Finally, the atomic fraction of $\mathrm{Co}, x$, for the $\mathrm{Co}_{\mathrm{x}} \mathrm{Fe}_{(8 / 3-2 \times / 3)} \mathrm{O}_{4}$ formula unit in cobalt doped maghemite is obtained from the following equation:

$\frac{C_{C o}}{C_{F e}}=\frac{3 x}{8-2 x}$

The EDS spectra acquired from individual particles of the CoFe10, CoFe66 and $\mathrm{CoFe} 94$ samples, shown in Fig. 2A, 2B, and 2C, respectively, give results for the Co atomic fraction, $x$, which are similar to what is obtained for groups of particles, as it can be inferred from the 3D graphs reported in Figure 3, showing the EDS spectra (in the range 5.8-7.6 keV) as a function of energy and Co content $x$ (as evaluated by ICP-AES), averaged over several spectra, obtained from groups of particles of each sample. The average values from groups of particles of each sample are 
also shown in Table I. For the three samples a reasonable agreement with the ICP-AES measurements has been found, taking into account the uncertainties on the $x$ value, calculated by propagating the uncertainties over the fit parameters (peak intensity and width of the gaussian).

HRTEM images of the same samples, CoFe10, CoFe66 and CoFe94, were also obtained. These images show that in all cases the nanoparticles are monocrystalline with no evidence of any structural defects. The 2D-Fast Fourier Transform of the HRTEM images points out that all the analyzed nanoparticles are constituted by a face centred cubic packing ascribable to cobalt-doped maghemite (S.G: $F d 3 m$ ). It should be pointed out that the small variation in the lattice parameter that is expected as a function of Co doping cannot be distinguished by HRTEM. Figures 4-6 show some HRTEM images of the CoFe10, CoFe66 and CoFe94, respectively. For each sample HRTEM images of two nanoparticles are shown, each one with the corresponding numerical diffractogram (i.e., the filtered 2D-Fast Fourier Transform) and with the Fourier filtered image of the chosen particle.

\subsection{XANES and EXAFS}

The XANES spectra at the Fe and Co K-edges for all the samples, which are reported in Figure $7 \mathrm{~A}$ and $\mathrm{B}$, respectively, along with those of a bulk cobalt ferrite sample, indicate that only $\mathrm{Fe}^{3+}$ and $\mathrm{Co}^{2+}$ are present. In fact, the position of the main absorption edge of all the samples are very close to the bulk Co ferrite sample at both edges and also to $\gamma-\mathrm{Fe}_{2} \mathrm{O}_{3}$ at the $\mathrm{Fe} \mathrm{K}$-edge and to $\mathrm{CoO}$ at the Co K-edge.

A small pre-edge peak is detectable in the XANES spectra at both the Fe and Co K-edges indicating that the excited atom site has a lack of centrosymmetry. In fact, it is well know that the pre-peak is stronger if the excited atom is located in a tetrahedral site compared to an octahedral site. A comparison of the spectra at the Fe K-edge and the Co K-edge show that in all samples the pre-edge peak is stronger at the $\mathrm{Fe} \mathrm{K}$-edge than at the Co K-edge pointing out that a large fraction of $\mathrm{Fe}$ is located in tetrahedral sites and at the same time cobalt is preferentially in octahedral sites. 
These findings concur to indicate a high degree of inversion in all samples. No strong differences are detectable in the samples as a function of composition.

The $\mathrm{k}^{3} \chi(\mathrm{k})$ EXAFS functions at the Fe and Co K-edge of all the samples together with that of bulk cobalt ferrite are reported in Fig. $8 \mathrm{~A}$ and $8 \mathrm{~B}$, respectively, and the corresponding FTs are reported in Figure 9A and 9B, respectively.

Qualitative information on the inversion degree can be obtained from the shape of the Fourier Transforms, while quantitative information are obtained from fitting the data in $k$ space. In particular, the region between 2.5 and $4 \AA$ of the FTs, where the most important contributions are the metal-metal distances, provides qualitative but very helpful information on the degree of inversion of the spinel structure. In these spinel structures, the distance between two octahedral sites is approximately $3 \AA$, while the distance between two tetrahedral sites and the distance between one tetrahedral and one octahedral sites are both longer, about $3.5 \AA$. Taking into account that in a normal spinel the bivalent cations are all located in tetrahedral sites, and in an inverse spinel they are all located in octahedral sites, the contribution around $3 \AA$ in the FT at the K-edge of the bivalent cation is expected to decrease progressively, down to zero, going from an inverse to a normal spinel. An opposite trend is expected for the contribution around $3.5 \AA$ which should increase progressively from an inverse to a normal spinel. Variations in the degree of inversion also affect the same region of the FT at Fe K-edge. However, in this case the effect is less pronounced because in both normal and inverse spinel $\mathrm{Fe}^{3+}$ ions occupies octahedral sites, the proportion varying from $100 \%$ in normal spinels to $50 \%$ in inverse spinels.

Two unresolved peaks are observed in this region for all samples at both edges, indicating that a partially inverted spinel structure is present. No big differences are evident in the series of samples indicating that the distribution of the ions between the tetrahedral and octahedral sites does not change significantly with composition. However, some small differences can be pointed out, for example $\mathrm{CoFe} 10$ seems to be more disordered (due to smaller average diameter of the particles) compared to the other samples, since the peaks have a lower amplitude. 
At the Fe K-edge the contribution at $3 \AA$ is slightly decreasing from CoFe19 to CoFe53 and then increases slightly for CoFe66 and CoFe94. The contribution at $3.5 \AA$ increases slightly from CoFe19 to CoFe94.

At the Co K-edge CoFe19 and CoFe35 are very similar, then $\mathrm{CoFe} 38, \mathrm{CoFe} 42$ and $\mathrm{CoFe} 53$ are all different, showing first an increase of the contribution at $3.5 \AA$, then an increase of the contribution at $3 \AA$ and then a decrease of the same contribution. CoFe66 and CoFe94 are quite similar to each other.

The results of the fitting of the samples and of a pure cobalt ferrite bulk sample are reported in Fig. 8A/9A and 8B/9B at the Fe and Co K-edge, respectively and the best fitting parameters are reported in Table 2-5. The values of the inversion degree, $i$, is also reported in Table I.

The EXAFS data of all the samples have been fitted considering as starting values the parameters found in the literature for the pure cobalt ferrite spinel structure, i.e. a highly inverted spinel with iron and cobalt cations distributed between the tetrahedral (A) and octahedral (B) sites available in the close packing of oxygen anions. ${ }^{29}$ Therefore, the fitting at both Fe and Co K-edges was done considering two clusters of atoms, one having the absorbing atom in a tetrahedral site (hereafter called $\mathrm{Fe}_{\mathrm{A}}$ or $\mathrm{Co}_{\mathrm{A}}$ ) and the other having the absorbing atom in an octahedral site (hereafter called $\mathrm{Fe}_{\mathrm{B}}$ or $\mathrm{Co}_{\mathrm{B}}$ ). $\mathrm{As} \mathrm{Fe}$ and $\mathrm{Co}$ have similar backscattering amplitudes, only $\mathrm{Fe}$ backscatterers were considered at the Fe edge and only Co backscatterers at the Co edge in order to simplify the fitting. With the same aim to simplify the fitting, the presence of vacancies was not taken into account, since even in pure maghemite only 0.33 vacancies are present. The fitting was performed keeping fixed the coordination numbers, $N_{i}$, of both the octahedral and tetrahedral sites and allowing small variations of $R_{i}$ (within the experimental error), whilst $2 \sigma_{i}{ }^{2}$ and the parameter EF were left free to vary. The distribution of bivalent and trivalent cations between tetrahedral (A) sites and octahedral (B) sites can be specified by a single variable parameter, $\mathrm{xB}\left(\mathrm{Co}^{2+}\right)$, i.e the fraction of $\mathrm{Co}^{2+}$ cations in octahedral sites, which also corresponds to the inversion parameter, $i$. The 
occupancy of tetrahedral (A) sites is determined from $\mathrm{xA}=1-\mathrm{xB}$. The fraction of $\mathrm{Fe} 3+$ in octahedral sites must satisfy the requirement $\mathrm{xB}\left(\mathrm{Fe}^{3+}\right)=\left(2-\mathrm{xB}\left(\mathrm{Co}^{2}+\right)\right) / 2$.

The fitting of the EXAFS data indicates for all samples a degree of inversion close to 0.7 , which is also very similar to the inversion degree determined in the bulk cobalt ferrite sample. In particular, the degree of inversion of the pure bulk cobalt ferrite sample is $0.69 \pm 0.03$ and that of the Co doped maghemite nanoparticles ranges between $0.73 \pm 0.03$ for the sample with the lowest doping to $0.71 \pm 0.03$ for the one with the highest doping.

\section{Discussion}

XANES results point out that all $\mathrm{Fe}$ is in the $3+$ oxidation state and $\mathrm{Co}$ in the $2+$ oxidation state and EXAFS FTs are typical of a highly inverted spinel phase similar to stoichiometric bulk cobalt ferrite, whose structure is also strictly related to pure maghemite. In order to confirm that the synthesized samples are composed of cobalt-doped nanoparticles, rather than a physical mixture of maghemite and cobalt ferrite nanoparticles, an EDS analysis was performed on samples with different cobalt doping. The recorded EDS spectra allows us to conclude that cobalt-doped nanoparticles with the desired composition were obtained. HRTEM indicates that all nanoparticles are defect free single nanocrystals.

The fitting of the EXAFS data indicates that the degree of inversion does not change noticeably as a function of composition of cobalt-doped maghemite nanoparticles. Compared to magnetite, $\mathrm{Fe}_{3} \mathrm{O}_{4}$, which is an inverse spinel with ferrous ions in octahedral sites and ferric ions equally distributed between octahedral and tetrahedral sites, maghemite is a ferric oxide with an inverse spinel structure that contains, as in magnetite, cations in tetrahedral and octahedral positions, the only difference being the presence of vacancies, usually in octahedral positions, to compensate for the increased positive charge. Going from pure maghemite to pure $\mathrm{CoFe}_{2} \mathrm{O}_{4} 0.33$ vacancies are progressively occupied while $\mathrm{Fe}^{3+}$ is substituted by $\mathrm{Co}^{2+}$. If in maghemite the vacancies are preferentially located into the octahedral sites, the ratio between octahedral and tetrahedral occupied 
sites should be lower than 2, which is the typical value of a spinel without vacancies. The observed XANES and EXAFS results which do not show any appreciable difference in the pre-peak intensity and in the degree of inversion as a function of Co doping seem to suggest that $\mathrm{Co}^{2+}$ does not show a preference in occupying a specific site and the ratio between octahedral and tetrahedral occupied sites remains practically constant.

To take into account the possibility that the divalent ions can sit either in a tetrahedral or in an octahedral cavity, we can write the composition of the nanoparticles as:

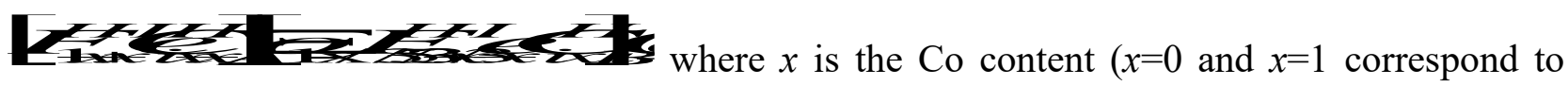
stoichiometric maghemite and cobalt ferrite, respectively), $i$ is the inversion parameter and $\Xi$ represents vacancies, typical of the maghemite structure.

The results of the fitting also indicate that all the distances between $\mathrm{Fe}$, $\mathrm{Co}$ and $\mathrm{O}$ are not influenced by the change in composition even if X-ray diffraction patterns reported in ref. 12 indicated that the cell parameter progressively increases as the cobalt content increases. These results indicate that the variation in the cell parameter is more related to the filling of the vacancies more than to a local variation of the atomic distances.

Since the degree of inversion is very similar in all samples, the peculiar trend with the cobalt content, which was observed in the magnetic and magneto-optical properties of these nanoparticles, 12 cannot be attributed to a non homogeneous cation occupation of the A and B sites, varying with the Co content, but must be related to the intrinsic magnetic characteristics of Co-substituted ferrites. ${ }^{12}$ This finding has great interest, especially in biomedical applications (hyperthermia, MRI), where cobalt ferrite has been demonstrated to be a much more efficient heat mediator and contrast agent than standard iron oxides, although its use is hampered by Co toxicity. 


\section{Conclusions}

This study has shown that Co-substituted maghemite nanoparticles are obtained via thermal decomposition of $\mathrm{Co}$ and $\mathrm{Fe}$ acetylacetonates, properly mixed in order to reach the Co content desired. The obtained nanoparticles are single crystalline and they all have the composition of the $\mathrm{Co} / \mathrm{Fe}$ ratio used in the synthesis without segregation of pure iron oxide and/or pure cobalt ferrite. The size distribution is bimodal for the sample with the lowest Co substitution, with a population of nanoparticles with size between 2 and $3 \mathrm{~nm}$ and another with size bewteen 5 and $8 \mathrm{~nm}$. On the other hand a single population of nanoparticles with sizes between 7 and $11 \mathrm{~nm}$ is observed in the samples with the largest cobalt substitution. For all samples a similar degree of inversion was observed, which is close to 0.7 .

Una riga per chiudere.

\section{References}

1) Santos, P. T. A.; Costa, A. C. F. M. ; Kiminami, R. H. G. A.; Andrade, H. M. C.; Lira, H. L.; Gama, L. J. Alloys Compd. 2009, 483, 399;

2) Maier-Hauff, K.; Ulrich, F.; Nestler, D.; Niehoff, H.; Wust, P.; Thiesen, B.; Orawa, H.; Budach, V.; Jordan, A. J. Neurooncol. 2011, 103, 317;

3) Challa, S. S. R. K.; Faruq, M. Adv. Drug. Deliver. Rev. 2011, 63, 789;

4) Lekshmi, I. C.; Buonsanti, R.; Nobile, C.; Rinaldi, R.; Cozzoli, P. D.; Maruccio, G. ACSNano 2011, 5, 1731;

5) Sickafus, K. E.; Wills, J. M. J. Am. Ceram. Soc. 1999, 82, 12, 3279.

6) Harris, V. G.; Koon, N. C.; Williams, C. M.; Zhang, Q.; Abe, M.; Kirkland, J. P. Appl. Phys. Lett. 1996, 68, 15.

7) Zhang, Z. J.; Wang, Z. L.; Chakoumakos, B. C.; Yin, J. S. J. Am. Chem. Soc. 1998, 120, 1800. 
8) Carta, D.; Casula, M. F.; Falqui, A.; Loche, D.; Mountjoy, G.; Sangregorio, C.; Corrias, A. J. Phys. Chem. C 2009

9) Zhang, Z. J.; Wang, Z. L.; Chakoumakos, B. C.; Yin, J. S. J. Am. Chem. Soc.1998, 120, 1800

10) Tang, Z. X.; Sorensen, C. M.; Klabunde, K. J.; Hadjipanayis, G. C. Phys. Rev. Lett. 1991, 67, 3602.

11) Schultz-Sikma, E. A.; Joshi, H. M.; Ma, Q.; MacRenaris, K. W.; Eckermann, A. L.; Dravid, V. P.; Meade, T. J. Chem. Mater. 2011

12) E. Fantechi, G. Campo, D. Carta, A. Corrias, C. de Julián Fernández, D. Gatteschi, C. Innocenti, F. Pineider, F. Rugi, C. Sangregorio, J. Phys. Chem. C 2012, 116, 8261.

13) A. Corrias, G. Ennas, G. Mountjoy, G. Paschina, Phys. Chem. Chem. Phys. 2, 1045, 2000.

14) Carta, D.; Mountjoy, G.; Navarra, G.; Casula, M. F.; Loche, D.; Marras, S.; Corrias, A. J. Phys. Chem. C 2007, 111, 6308.

15) Carta, D.; Loche, D.; Mountjoy, G. ; Navarra, G.; Corrias, A. J. Phys. Chem. C 2008 112, 15623.

16) Carta, D.; Casula, M. F.; Mountjoy, G. ; Corrias, A. Phys. Chem. Chem. Phys. 10, 3108, 2008

17) Nakagawa, T,; Yuya, M.; Tachibana, T.; Takada, Y.; Nitani, H.; Emura, S.; Yamamoto, T. A. J. Magn. Magn. Mater. 2005, 288, 366.

18) Harris, V.G.; Koon, N. C.; Williams, C. M. Zhang, Q.; Abe, M.; Kirkland J. P. Appl. Phys. Lett. 1996, 68, 15.

19) Carta, D.; Casula, M. F.; Falqui, A.; Loche, D.; Mountjoy, G. ; Sangregorio C.; Corrias, A. J. Phys. Chem. C, 113, 8606, 2009.

20) Kim, S. J.; Myoung, B. R.; Kim, C. S. J. Appl. Phys. 2003, 93, 10.

21)Lee, J.-G.; Park, J. Y.; Kim, C. S. J. Mater. Sci. 1998, 33, 3965 
22) Bianconi, A. X-ray absorption: principles, applications, techniques of EXAFS, SEXAFS and XANES Koninbsberger, D. C., Prins, R., Eds; Wiley, New York, Cap.11, 1987.

23) Klementiev, K.V.; Appl. Phys. 2001, 34, 209.

24) S. Tomic, B. G. Searle, A. Wander, N.M. Harrison, A.J. Dent, J.F.W. Mosselmans, J.E. Inglesfield, CCLRC Technical Report DL-TR-2005-001, ISSN 1362-0207, (2005).

25) Gurman, S. J.; Binsted; N.; Ross, I. J. Phys. C 1984, 17, 143.

26) Von Barth, U.; Hedin, L. J. Phys C 1972, 51629.

27) Crozier, E. D. Nucl. Instr. Method Phys. Res. B 1997, 133, 134.

28) B. Fultz, M. Howe, Transmission Electron Microscopy and Diffractometry of Materials, second ed., Springer-Verlag, Berlin Heidelberg (2002)

29) Inoue, T. J. Electrochem. Soc. Japan 1955, 23, 24. 
Table I. List of the Co-doped maghemite nanoparticles and their cobalt content (x), in the $\mathrm{Co}_{\mathrm{x}} \mathrm{Fe}(8 / 3-$ 2x/3) $\mathrm{O}_{4}$ formula unit, as determined by ICP-AES and, for samples $\mathrm{CoFe} 10, \mathrm{CoFe} 66$ and $\mathrm{CoFe} 94$, as measured by averaging EDS spectra recorded from groups of particles in STEM mode; inversion degree $(i)$.

\begin{tabular}{|c|c|c|c|}
\hline Sample & $x\left(I C P \_A E S\right)$ & $x(E D S)$ & $i$ \\
\hline CoFe10 & 0.10 & $0.11 \pm 0.03$ & $0.73 \pm 0.03$ \\
\hline CoFe19 & 0.19 & & $0.72 \pm 0.03$ \\
\hline CoFe35 & 0.35 & & $0.70 \pm 0.03$ \\
\hline CoFe38 & 0.38 & & $0.71 \pm 0.03$ \\
\hline CoFe42 & 0.42 & & $0.71 \pm 0.03$ \\
\hline CoFe53 & 0.53 & & $0.71 \pm 0.03$ \\
\hline CoFe66 & 0.66 & $0.72 \pm 0.03$ & $0.72 \pm 0.03$ \\
\hline CoFe94 & 0.94 & $0.98 \pm 0.04$ & $0.71 \pm 0.03$ \\
\hline
\end{tabular}


Table 2. Interatomic distances (R), Debye-Waller Factors $(\sigma)$ and EF obtained by fitting the experimental $\mathrm{k}^{3} \chi(\mathrm{k})$ of $\mathrm{CoFe} 10$ and $\mathrm{CoFe} 19$ at the Fe and Co K-edge; coordination numbers (N) were kept fixed as described in the text.

\begin{tabular}{|c|c|c|c|c|c|c|c|c|c|c|c|c|c|c|c|}
\hline \multicolumn{8}{|c|}{ Fe-K-edge } & \multicolumn{8}{|c|}{ Co-K-edge } \\
\hline & \multicolumn{3}{|c|}{ CoFe10 } & & \multicolumn{3}{|c|}{ CoFe19 } & & \multicolumn{3}{|c|}{ CoFe10 } & & \multicolumn{3}{|c|}{ CoFe19 } \\
\hline $\begin{array}{l}\text { Sites A } \\
\mathbf{3 6 ( 3 ) \%}\end{array}$ & $\mathrm{R}(\AA)$ & $\mathrm{N}$ & $2 \sigma^{2}$ & $\begin{array}{l}\text { Sites A } \\
\text { 35(2)\% }\end{array}$ & $\mathrm{R}(\AA)$ & $\mathrm{N}$ & $2 \sigma^{2}$ & $\begin{array}{l}\text { Sites A } \\
27(3) \%\end{array}$ & $\mathrm{R}(\AA)$ & $\mathrm{N}$ & $2 \sigma^{2}$ & $\begin{array}{l}\text { Sites A } \\
28(3) \%\end{array}$ & $\mathrm{R}(\AA)$ & $\mathrm{N}$ & $2 \sigma^{2}$ \\
\hline $\mathrm{O}$ & $1.88(1)$ & 4.0 & $0.020(2)$ & $\mathrm{O}$ & $1.87(1)$ & 4.0 & $0.023(3)$ & $\mathrm{O}$ & $1.89(3)$ & 4.0 & $0.030(3)$ & $\mathrm{O}$ & $1.89(2)$ & 4.0 & $0.020(3)$ \\
\hline $\mathrm{Fe}$ & $3.45(2)$ & 12.0 & $0.031(4)$ & $\mathrm{Fe}$ & $3.48(1)$ & 12.0 & $0.023(1)$ & $\mathrm{Co}$ & $3.47(6)$ & 12.0 & $0.033(5)$ & $\mathrm{Co}$ & $3.47(4)$ & 12.0 & $0.028(5)$ \\
\hline $\mathrm{O}$ & $3.49(2)$ & 12.0 & $0.029(4)$ & $\mathrm{O}$ & $3.49(3)$ & 12.0 & $0.030(6)$ & $\mathrm{O}$ & $3.51(3)$ & 12.0 & $0.033(3)$ & $\mathrm{O}$ & $3.50(5)$ & 12.0 & $0.029(6)$ \\
\hline $\mathrm{Fe}$ & $3.51(8)$ & 4.0 & $0.030(8)$ & $\mathrm{Fe}$ & $3.56(8)$ & 4.0 & $0.030(8)$ & $\mathrm{Co}$ & $3.54(2)$ & 4.0 & $0.032(5)$ & $\mathrm{Co}$ & $3.55(4)$ & 4.0 & $0.032(3)$ \\
\hline $\begin{array}{l}\text { Sites B } \\
64(2) \%\end{array}$ & $\mathrm{R}(\AA)$ & $\mathrm{N}$ & $2 \sigma^{2}$ & $\begin{array}{l}\text { Sites B } \\
\mathbf{6 5}(2) \%\end{array}$ & $\mathrm{R}(\AA)$ & $\mathrm{N}$ & $2 \sigma^{2}$ & $\begin{array}{l}\text { Sites B } \\
\mathbf{7 3 ( 3 ) \%}\end{array}$ & $\mathrm{R}(\AA)$ & $\mathrm{N}$ & $2 \sigma^{2}$ & $\begin{array}{l}\text { Sites B } \\
72(3) \%\end{array}$ & $\mathrm{R}(\AA)$ & $\mathrm{N}$ & $2 \sigma^{2}$ \\
\hline $\mathrm{O}$ & $1.99(1)$ & 6.0 & $0.019(1)$ & $\mathrm{O}$ & $1.99(1)$ & 6.0 & $0.017(1)$ & $\mathrm{O}$ & $2.06(1)$ & 6.0 & $0.010(1)$ & $\mathrm{O}$ & $2.07(1)$ & 6.0 & $0.010(2)$ \\
\hline $\mathrm{Fe}$ & 3.01(1) & 6.0 & $0.030(2)$ & $\mathrm{Fe}$ & $2.99(1)$ & 6.0 & $0.020(1)$ & $\mathrm{Co}$ & $2.98(2)$ & 6.0 & $0.033(4)$ & $\mathrm{Co}$ & $2.97(1)$ & 6.0 & $0.023(2)$ \\
\hline $\mathrm{Fe}$ & $3.46(1)$ & 6.0 & $0.031(3)$ & $\mathrm{Fe}$ & $3.48(1)$ & 6.0 & $0.023(2)$ & $\mathrm{Co}$ & $3.47(2)$ & 6.0 & $0.033(6)$ & $\mathrm{Co}$ & $3.47(3)$ & 6.0 & $0.028(4)$ \\
\hline $\mathrm{O}$ & $3.56(7)$ & 2.0 & $0.031(8)$ & $\mathrm{O}$ & $3.56(5)$ & 2.0 & $0.023(6)$ & $\mathrm{O}$ & $3.56(6)$ & 2.0 & $0.033(2)$ & $\mathrm{O}$ & $3.57(2)$ & 2.0 & $0.028(4)$ \\
\hline $\mathrm{O}$ & $3.70(2)$ & 6.0 & $0.031(7)$ & $\mathrm{O}$ & $3.68(3)$ & 6.0 & $0.024(8)$ & $\mathrm{O}$ & $3.62(2)$ & 6.0 & $0.033(5)$ & $\mathrm{O}$ & $3.58(2)$ & 6.0 & $0.029(2)$ \\
\hline & \multicolumn{3}{|c|}{$\mathrm{EF}=-0.7(2)$} & & \multicolumn{3}{|c|}{$\mathrm{EF}=-0.8(2)$} & & \multicolumn{3}{|c|}{$\mathrm{EF}=-0.3(4)$} & & \multicolumn{3}{|c|}{$\mathrm{EF}=0.4(3)$} \\
\hline & \multicolumn{3}{|c|}{$\mathrm{R}$-factor $=24 \%$} & & \multicolumn{3}{|c|}{$\mathrm{R}$-factor $=27 \%$} & & \multicolumn{3}{|c|}{$\mathrm{R}$-factor $=45 \%$} & & \multicolumn{3}{|c|}{$\mathrm{R}$-factor $=37 \%$} \\
\hline & \multicolumn{3}{|c|}{$\mathrm{R}^{*}$-factor $=16 \%$} & & \multicolumn{3}{|c|}{$\mathrm{R} *$-factor $=14 \%$} & & \multicolumn{3}{|c|}{$\mathrm{R}^{*}$-factor $=35 \%$} & & \multicolumn{3}{|c|}{$\mathrm{R}^{*}$-factor $=18 \%$} \\
\hline
\end{tabular}


Table 3. Interatomic distances (R), Debye-Waller Factors $(\sigma)$ and EF obtained by fitting the experimental $\mathrm{k}^{3} \chi(\mathrm{k})$ of $\mathrm{CoFe} 35$ and $\mathrm{CoFe} 38$ at the Fe and Co K-edge; coordination numbers (N) were kept fixed as described in the text.

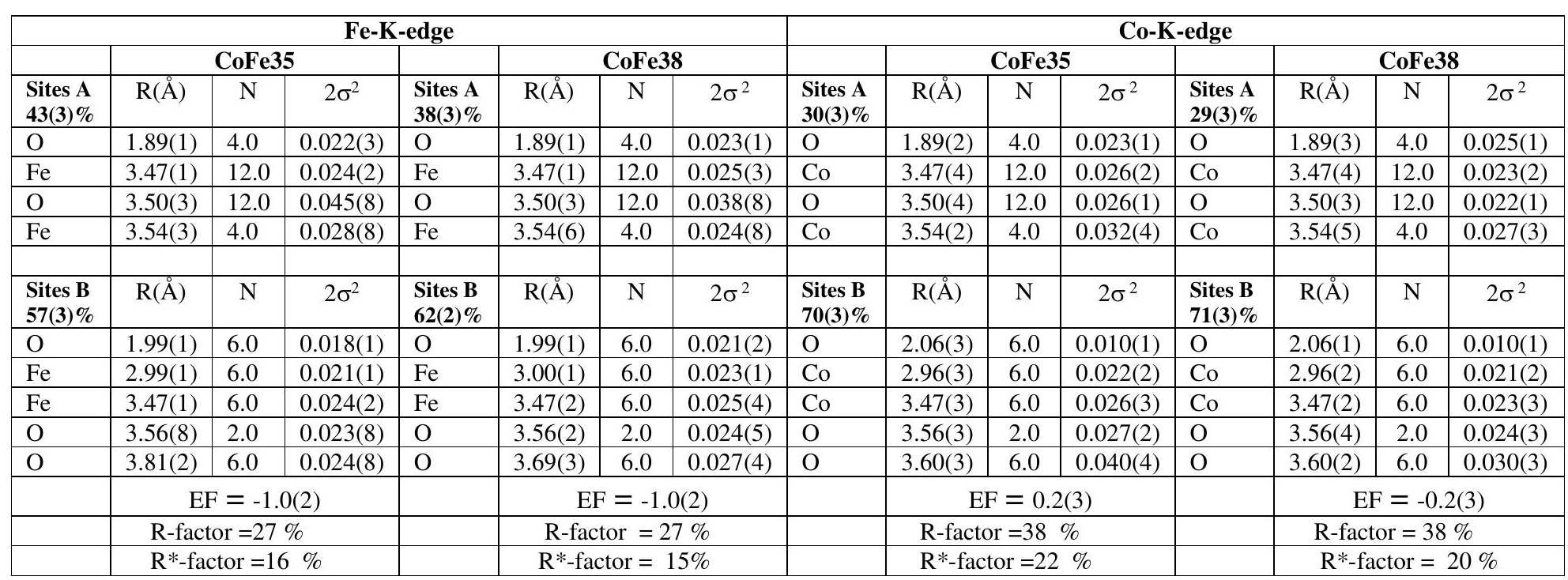


Table 4. Interatomic distances $(\mathrm{R})$, Debye-Waller Factors $(\sigma)$ and EF obtained by fitting the experimental $\mathrm{k}^{3} \chi(\mathrm{k})$ of $\mathrm{CoFe} 42$ and $\mathrm{CoFe} 53$ at the $\mathrm{Fe}$ and Co K-edge; coordination numbers $(\mathrm{N})$ were kept fixed as described in the text.

\begin{tabular}{|c|c|c|c|c|c|c|c|c|c|c|c|c|c|c|c|}
\hline \multicolumn{8}{|c|}{ Fe-K-edge } & \multicolumn{8}{|c|}{ Co-K-edge } \\
\hline & \multicolumn{3}{|c|}{ CoFe42 } & & \multicolumn{3}{|c|}{ CoFe53 } & & \multicolumn{3}{|c|}{ CoFe42 } & & \multicolumn{3}{|c|}{ CoFe53 } \\
\hline $\begin{array}{l}\text { Sites A } \\
\text { 35(2)\% }\end{array}$ & $\mathrm{R}(\AA)$ & $\mathrm{N}$ & $2 \sigma^{2}$ & $\begin{array}{l}\text { Sites A } \\
\mathbf{3 5}(\mathbf{2}) \%\end{array}$ & $\mathrm{R}(\AA)$ & $\mathrm{N}$ & $2 \sigma^{2}$ & $\begin{array}{l}\text { Sites A } \\
29(3) \% \\
\end{array}$ & $R(\AA)$ & $\mathrm{N}$ & $2 \sigma^{2}$ & $\begin{array}{l}\text { Sites A } \\
29(3) \%\end{array}$ & $R(\AA)$ & $\mathrm{N}$ & $2 \sigma^{2}$ \\
\hline $\mathrm{O}$ & $1.88(1)$ & 4.0 & $0.021(3)$ & $\mathrm{O}$ & $1.89(1)$ & 4.0 & $0.016(2)$ & $\mathrm{O}$ & $1.89(3)$ & 4.0 & $0.026(1)$ & $\mathrm{O}$ & $1.89(3)$ & 4.0 & $0.026(3)$ \\
\hline $\mathrm{Fe}$ & $3.47(1)$ & 12.0 & $0.023(2)$ & $\mathrm{Fe}$ & $3.47(2)$ & 12.0 & $0.022(5)$ & $\mathrm{Co}$ & $3.47(4)$ & 12.0 & $0.022(1)$ & Co & $3.48(5)$ & 12.0 & $0.025(4)$ \\
\hline $\mathrm{O}$ & $3.50(2)$ & 12.0 & $0.024(6)$ & $\mathrm{O}$ & $3.49(3)$ & 12.0 & $0.021(8)$ & $\mathrm{O}$ & $3.49(4)$ & 12.0 & $0.020(2)$ & $\mathrm{O}$ & $3.50(3)$ & 12.0 & $0.026(3)$ \\
\hline $\mathrm{Fe}$ & $3.55(5)$ & 4.0 & $0.026(7)$ & $\mathrm{Fe}$ & $3.55(3)$ & 4.0 & $0.030(5)$ & $\mathrm{Co}$ & $3.55(5)$ & 4.0 & $0.027(3)$ & $\mathrm{Co}$ & $3.55(3)$ & 4.0 & $0.032(3)$ \\
\hline $\begin{array}{l}\text { Sites B } \\
65(2) \%\end{array}$ & $\mathrm{R}(\AA)$ & $\mathrm{N}$ & $2 \sigma^{2}$ & $\begin{array}{l}\text { Sites B } \\
65(2) \%\end{array}$ & $\mathrm{R}(\AA)$ & $\mathrm{N}$ & $2 \sigma^{2}$ & $\begin{array}{l}\text { Sites B } \\
71(3) \%\end{array}$ & $\mathrm{R}(\AA)$ & $\mathrm{N}$ & $2 \sigma^{2}$ & $\begin{array}{l}\text { Sites B } \\
71(3) \% \\
\end{array}$ & $\mathrm{R}(\AA)$ & $\mathrm{N}$ & $2 \sigma^{2}$ \\
\hline $\mathrm{O}$ & $1.99(1)$ & 6.0 & $0.021(1)$ & $\mathrm{O}$ & $1.99(1)$ & 6.0 & $0.021(2)$ & $\mathrm{O}$ & $2.06(1)$ & 6.0 & $0.011(1)$ & $\mathrm{O}$ & $2.06(3)$ & 6.0 & $0.012(1)$ \\
\hline $\mathrm{Fe}$ & $2.99(1)$ & 6.0 & $0.023(2)$ & $\mathrm{Fe}$ & $2.99(1)$ & 6.0 & $0.023(1)$ & $\mathrm{Co}$ & $2.95(1)$ & 6.0 & $0.017(1)$ & Co & $2.97(4)$ & 6.0 & $0.022(1)$ \\
\hline $\mathrm{Fe}$ & $3.47(1)$ & 6.0 & $0.023(2)$ & $\mathrm{Fe}$ & $3.48(2)$ & 6.0 & $0.022(2)$ & $\mathrm{Co}$ & $3.47(2)$ & 6.0 & $0.022(6)$ & $\mathrm{Co}$ & $3.48(3)$ & 6.0 & $0.025(3)$ \\
\hline $\mathrm{O}$ & $3.56(1)$ & 2.0 & $0.024(8)$ & $\mathrm{O}$ & $3.56(5)$ & 2.0 & $0.022(3)$ & $\mathrm{O}$ & $3.56(3)$ & 2.0 & $0.023(3)$ & $\mathrm{O}$ & $3.56(4)$ & 2.0 & $0.024(3)$ \\
\hline $\mathrm{O}$ & $3.69(3)$ & 6.0 & $0.028(8)$ & $\mathrm{O}$ & $3.68(3)$ & 6.0 & $0.028(6)$ & $\mathrm{O}$ & $3.61(3)$ & 6.0 & $0.021(1)$ & $\mathrm{O}$ & $3.66(3)$ & 6.0 & $0.034(5)$ \\
\hline & \multicolumn{3}{|c|}{$\mathrm{EF}=-1.2(2)$} & & \multicolumn{3}{|c|}{$\mathrm{EF}=-1.4(2)$} & & \multicolumn{3}{|c|}{$E F=-0.4(3)$} & & \multicolumn{3}{|c|}{$E F=-0.3(3)$} \\
\hline & \multicolumn{3}{|c|}{$\mathrm{R}$-factor $=29 \%$} & & \multicolumn{3}{|c|}{ R-factor $=27 \%$} & & \multicolumn{3}{|c|}{$\mathrm{R}$-factor $=40 \%$} & & \multicolumn{3}{|c|}{$\mathrm{R}$-factor $=40 \%$} \\
\hline & \multicolumn{3}{|c|}{$\mathrm{R}^{*}$-factor $=15 \%$} & & \multicolumn{3}{|c|}{$\mathrm{R}^{*}$-factor $=14 \%$} & & \multicolumn{3}{|c|}{$\mathrm{R} *$-factor $=19 \%$} & & \multicolumn{3}{|c|}{$\mathrm{R} *$-factor $=22 \%$} \\
\hline
\end{tabular}


Table 5. Interatomic distances $(\mathrm{R})$, Debye-Waller Factors $(\sigma)$ and EF obtained by fitting the experimental $\mathrm{k}^{3} \chi(\mathrm{k})$ of $\mathrm{CoFe} 66$ and $\mathrm{CoFe} 94$ at the $\mathrm{Fe}$ and Co K-edge; coordination numbers $(\mathrm{N})$ were kept fixed as described in the text.

\begin{tabular}{|c|c|c|c|c|c|c|c|c|c|c|c|c|c|c|c|}
\hline \multicolumn{8}{|c|}{ Fe-K-edge } & \multicolumn{8}{|c|}{ Co-K-edge } \\
\hline & \multicolumn{3}{|c|}{ CoFe66 } & & \multicolumn{3}{|c|}{ CoFe94 } & & \multicolumn{3}{|c|}{ CoFe66 } & & \multicolumn{3}{|c|}{ CoFe94 } \\
\hline $\begin{array}{l}\text { Sites A } \\
\text { 38(2)\% }\end{array}$ & $\mathrm{R}(\AA)$ & $\mathrm{N}$ & $2 \sigma^{2}$ & $\begin{array}{l}\text { Sites A } \\
\text { 35(2)\% }\end{array}$ & $\mathrm{R}(\AA)$ & $\mathrm{N}$ & $2 \sigma^{2}$ & $\begin{array}{l}\text { Sites A } \\
\mathbf{2 8 ( 3 ) \%}\end{array}$ & $\mathrm{R}(\AA)$ & $\mathrm{N}$ & $2 \sigma^{2}$ & $\begin{array}{l}\text { Sites A } \\
29(3) \%\end{array}$ & $\mathrm{R}(\AA)$ & $\mathrm{N}$ & $2 \sigma^{2}$ \\
\hline $\mathrm{O}$ & $1.88(1)$ & 4.0 & $0.019(3)$ & $\mathrm{O}$ & $1.88(1)$ & 4.0 & $0.016(3)$ & $\mathrm{O}$ & $1.89(3)$ & 4.0 & $0.022(4)$ & $\mathrm{O}$ & $1.89(2)$ & 4.0 & $0.022(4)$ \\
\hline $\mathrm{Fe}$ & $3.48(1)$ & 12.0 & $0.020(2)$ & $\mathrm{Fe}$ & $3.47(2)$ & 12.0 & $0.020(3)$ & $\mathrm{Co}$ & $3.47(3)$ & 12.0 & $0.020(3)$ & $\mathrm{Co}$ & $3.48(4)$ & 12.0 & $0.023(3)$ \\
\hline $\mathrm{O}$ & $3.50(4)$ & 12.0 & $0.022(5)$ & $\mathrm{O}$ & $3.50(3)$ & 12.0 & $0.018(5)$ & $\mathrm{O}$ & $3.50(5)$ & 12.0 & $0.020(3)$ & $\mathrm{O}$ & $3.50(3)$ & 12.0 & $0.022(3)$ \\
\hline $\mathrm{Fe}$ & $3.54(1)$ & 4.0 & $0.018(6)$ & $\mathrm{Fe}$ & $3.54(3)$ & 4.0 & $0.018(5)$ & Co & $3.53(4)$ & 4.0 & $0.026(2)$ & Co & $3.54(3)$ & 4.0 & $0.026(5)$ \\
\hline $\begin{array}{l}\text { Sites B } \\
68(2) \%\end{array}$ & $\mathrm{R}(\AA)$ & $\mathrm{N}$ & $2 \sigma^{2}$ & $\begin{array}{l}\text { Sites B } \\
\mathbf{6 5}(2) \%\end{array}$ & $\mathrm{R}(\AA)$ & $\mathrm{N}$ & $2 \sigma^{2}$ & $\begin{array}{l}\text { Sites B } \\
\mathbf{7 2 ( 3 ) \%}\end{array}$ & $\mathrm{R}(\AA)$ & $\mathrm{N}$ & $2 \sigma^{2}$ & $\begin{array}{l}\text { Sites B } \\
71(3) \%\end{array}$ & $\mathrm{R}(\AA)$ & $\mathrm{N}$ & $2 \sigma^{2}$ \\
\hline $\mathrm{O}$ & $2.00(1)$ & 6.0 & $0.020(2)$ & $\mathrm{O}$ & $2.00(1)$ & 6.0 & $0.019(2)$ & $\mathrm{O}$ & $2.06(1)$ & 6.0 & $0.011(1)$ & $\mathrm{O}$ & $2.06(1)$ & 6.0 & $0.012(1)$ \\
\hline $\mathrm{Fe}$ & $2.99(1)$ & 6.0 & $0.020(1)$ & $\mathrm{Fe}$ & $2.98(1)$ & 6.0 & $0.019(1)$ & $\mathrm{Co}$ & $2.95(1)$ & 6.0 & $0.017(1)$ & $\mathrm{Co}$ & $2.95(1)$ & 6.0 & $0.019(1)$ \\
\hline $\mathrm{Fe}$ & $3.48(1)$ & 6.0 & $0.020(2)$ & $\mathrm{Fe}$ & $3.47(3)$ & 6.0 & $0.020(2)$ & $\mathrm{Co}$ & $3.47(1)$ & 6.0 & $0.020(3)$ & $\mathrm{Co}$ & $3.48(2)$ & 6.0 & $0.023(3)$ \\
\hline $\mathrm{O}$ & $3.56(4)$ & 2.0 & $0.020(1)$ & $\mathrm{O}$ & $3.56(4)$ & 2.0 & $0.020(5)$ & $\mathrm{O}$ & $3.56(4)$ & 2.0 & $0.022(3)$ & $\mathrm{O}$ & $3.56(4)$ & 2.0 & $0.023(4)$ \\
\hline $\mathrm{O}$ & $3.68(2)$ & 6.0 & $0.020(5)$ & $\mathrm{O}$ & $3.68(3)$ & 6.0 & $0.020(6)$ & $\mathrm{O}$ & $3.60(2)$ & 6.0 & $0.023(2)$ & $\mathrm{O}$ & $3.66(2)$ & 6.0 & $0.023(2)$ \\
\hline & \multicolumn{3}{|c|}{$\mathrm{EF}=-1.9(2)$} & & \multicolumn{3}{|c|}{$\mathrm{EF}=-1.2(2)$} & & \multicolumn{3}{|c|}{$\mathrm{EF}=-0.6(3)$} & & \multicolumn{3}{|c|}{$E F=-0.6(3)$} \\
\hline & \multicolumn{3}{|c|}{ R-factor $=29 \%$} & & \multicolumn{3}{|c|}{ R-factor $=29 \%$} & & \multicolumn{3}{|c|}{$\mathrm{R}$-factor $=41 \%$} & & \multicolumn{3}{|c|}{ R-factor $=40 \%$} \\
\hline & \multicolumn{3}{|c|}{$\mathrm{R}^{*}$-factor $=13 \%$} & & \multicolumn{3}{|c|}{$\mathrm{R} *$-factor $=13 \%$} & & \multicolumn{3}{|c|}{$\mathrm{R} *$-factor $=16 \%$} & & \multicolumn{3}{|c|}{$\mathrm{R} *$-factor $=18 \%$} \\
\hline
\end{tabular}


Table 6. Interatomic distances $(\mathrm{R})$, Debye-Waller Factors $(\sigma)$ and EF obtained by fitting the experimental $\mathrm{k}^{3} \chi(\mathrm{k})$ of bulk $\mathrm{CoFe}_{2} \mathrm{O}_{4}$ at the $\mathrm{Fe}$ and $\mathrm{Co} \mathrm{K}$-edge; coordination numbers $(\mathrm{N})$ were kept fixed as described in the text.

\begin{tabular}{|c|c|c|c|c|c|c|c|}
\hline & \multicolumn{3}{|c|}{ Fe-K-edge } & & \multicolumn{3}{|c|}{ Co-K-edge } \\
\hline & \multicolumn{3}{|c|}{$\mathrm{CoFe}_{2} \mathrm{O}_{4}$} & & \multicolumn{3}{|c|}{$\mathrm{CoFe}_{2} \mathrm{O}_{4}$} \\
\hline $\begin{array}{l}\text { Sites A } \\
35(2) \%\end{array}$ & $\mathrm{R}(\AA)$ & $\mathrm{N}$ & $2 \sigma^{2}$ & $\begin{array}{l}\text { Sites A } \\
\text { 31(3) \% }\end{array}$ & $\mathrm{R}(\AA)$ & $\mathrm{N}$ & $2 \sigma^{2}$ \\
\hline $\mathrm{O}$ & $1.86(2)$ & 4.0 & $0.024(3)$ & $\mathrm{O}$ & $1.89(2)$ & 4.0 & $0.023(2)$ \\
\hline $\mathrm{Fe}$ & $3.48(1)$ & 12.0 & $0.014(3)$ & $\mathrm{Co}$ & $3.47(3)$ & 12.0 & $0.016(2)$ \\
\hline $\mathrm{O}$ & $3.50(4)$ & 12.0 & $0.014(2)$ & $\mathrm{O}$ & $3.50(3)$ & 12.0 & $0.015(3)$ \\
\hline $\mathrm{Fe}$ & $3.54(3)$ & 4.0 & $0.024(5)$ & $\mathrm{Co}$ & $3.54(4)$ & 4.0 & $0.026(3)$ \\
\hline $\begin{array}{l}\text { Sites B } \\
65(2) \%\end{array}$ & $\mathrm{R}(\AA)$ & $\mathrm{N}$ & $2 \sigma^{2}$ & $\begin{array}{l}\text { Sites B } \\
69(3) \%\end{array}$ & $\mathrm{R}(\AA)$ & $\mathrm{N}$ & $2 \sigma^{2}$ \\
\hline $\mathrm{O}$ & $1.98(1)$ & 6.0 & $0.013(2)$ & $\mathrm{O}$ & $2.06(1)$ & 6.0 & $0.010(2)$ \\
\hline $\mathrm{Fe}$ & $2.97(1)$ & 6.0 & $0.013(1)$ & $\mathrm{Co}$ & $2.95(1)$ & 6.0 & $0.010(2)$ \\
\hline $\mathrm{Fe}$ & $3.48(1)$ & 6.0 & $0.014(2)$ & $\mathrm{Co}$ & $3.47(2)$ & 6.0 & $0.016(3)$ \\
\hline $\mathrm{O}$ & $3.56(3)$ & 2.0 & $0.015(1)$ & $\mathrm{O}$ & $3.56(4)$ & 2.0 & $0.015(3)$ \\
\hline \multirow[t]{4}{*}{$\mathrm{O}$} & $3.68(3)$ & 6.0 & $0.017(2)$ & $\mathrm{O}$ & $3.66(5)$ & 6.0 & $0.015(3)$ \\
\hline & \multicolumn{3}{|c|}{$\mathrm{EF}=2.6(3)$} & & \multicolumn{3}{|c|}{$\mathrm{EF}=-1.2(1)$} \\
\hline & \multicolumn{3}{|c|}{$\mathrm{R}$-factor $=33 \%$} & & \multicolumn{3}{|c|}{$\mathrm{R}$-factor $=42 \%$} \\
\hline & \multicolumn{3}{|c|}{$\mathrm{R} *$-factor $=16 \%$} & & \multicolumn{3}{|c|}{$\mathrm{R} *$-factor $=18 \%$} \\
\hline
\end{tabular}


Figure Captions:

Figure 1: HAADF STEM images of samples: (a) CoFe10, (b) CoFe66, and (c) CoFe94. The bimodal population of nanoparticles in the sample $\mathrm{CoFe} 10$ is clearly observable.

Figure 2: HAADF images and EDS spectra (in the range 5.8-7.6 keV) of samples CoFe10 (A), CoFe66 (B) and CoFe94 (C) recorded from three individual particles selected in the image. The black curves are the experimental data, while the ones in blue, red and green are the gaussian fits of the three peaks. The calculated value of the Co content, $x$, is indicated in each spectrum, with absolute uncertainty of 0.09 for the CoFe10 sample, and 0.14 for both the CoFe66 and CoFe94 ones.

Figure 3: 3D graph reporting EDS spectra (in the range 5.8-7.6 keV) as a function of energy and Co content, $\mathrm{x}$, (as evaluated by ICP-AES) recorded from groups of particles of the samples CoFe10, CoFe66 and CoFe94 (the selected areas are enclosed in the red boxes in each HAADF image). The Co $\mathrm{K}_{\alpha}$ peak increases with the Co content, and corresponds to $x$ of $0.11,0.72$ and 0.98 , for the samples $\mathrm{CoFe} 10, \mathrm{CoFe} 66$ and $\mathrm{CoFe} 94$, respectively. The corresponding absolute uncertainties are reported in Table I.

Figure 4: HRTEM images of the CoFe10 sample. The numerical diffractograms of the particles surrounded by a square are also reported, together with their Fourier filtered images. The particle imaged in (a) is oriented along the [011] zone axis, that reported in (b) along the [001] one.

Figure 5: HRTEM images of the CoFe66 sample. The numerical diffractograms of the particles surrounded by a square are also reported, together with their Fourier filtered images. The particle imaged in (a) is oriented along the [-112] zone axis, that reported in (b) along the [011] one. 
Figure 6: HRTEM images of the CoFe94 sample. The numerical diffractograms of the particles surrounded by a square are also reported, together with their Fourier filtered images. The particle imaged in (a) is oriented along the [011] zone axis, that reported in (b) along the [001] one.

Figure 7: XANES spectra at the Fe (A) and Co (B) K-edges of the samples and of bulk cobalt ferrite.

Figure 8: $k^{3} \chi(k)$ spectra at the Fe (A) and Co (B) K-edges of the samples and of the bulk cobalt ferrite from experiment (-) and fit results $(\cdots)$.

Figure 9: Fourier transforms of $k^{3} \chi(k)$ spectra at the $\mathrm{Fe}(\mathrm{A})$ and $\mathrm{Co}(\mathrm{B}) \mathrm{K}$-edges of the samples and of bulk cobalt ferrite from experiment (-) and fit results $(\cdots)$. 


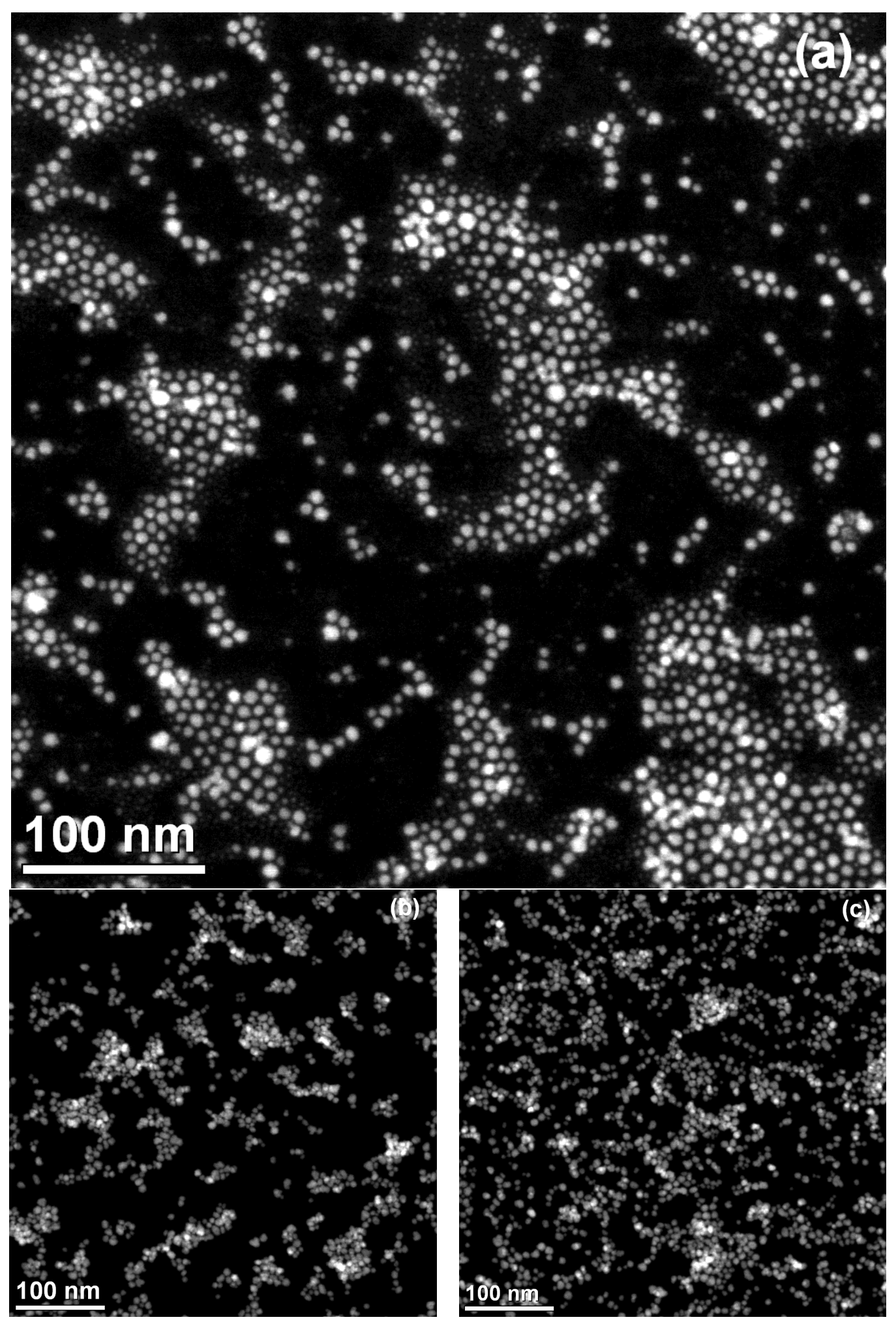

Figure 1 

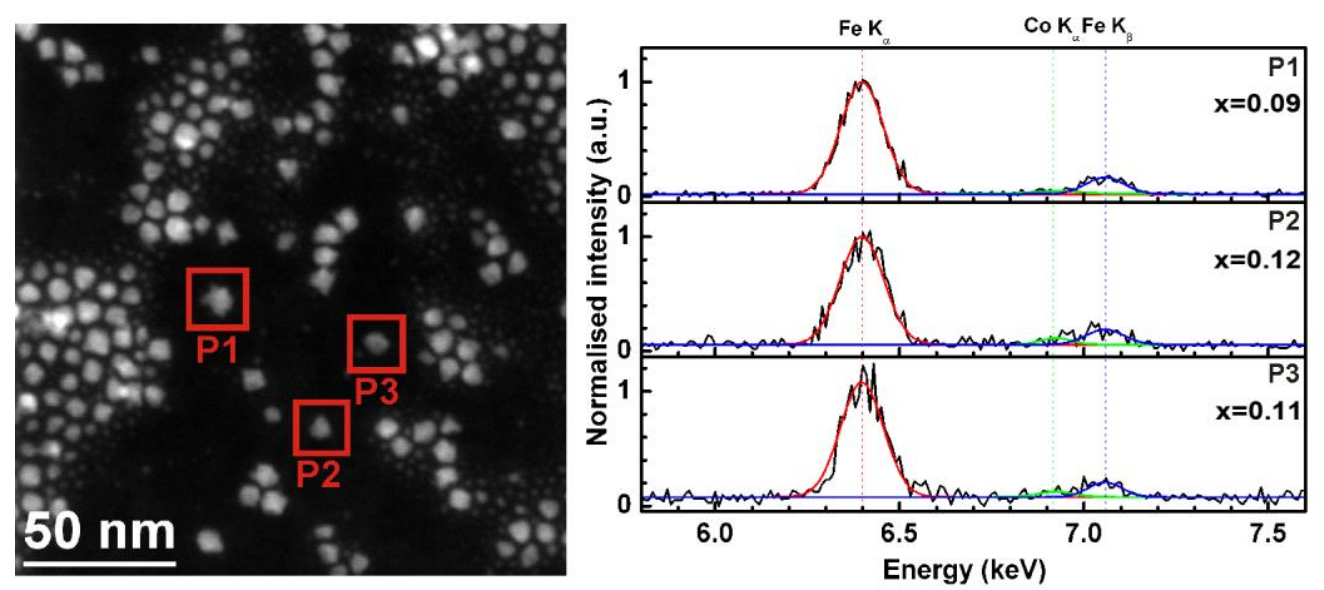

(A)
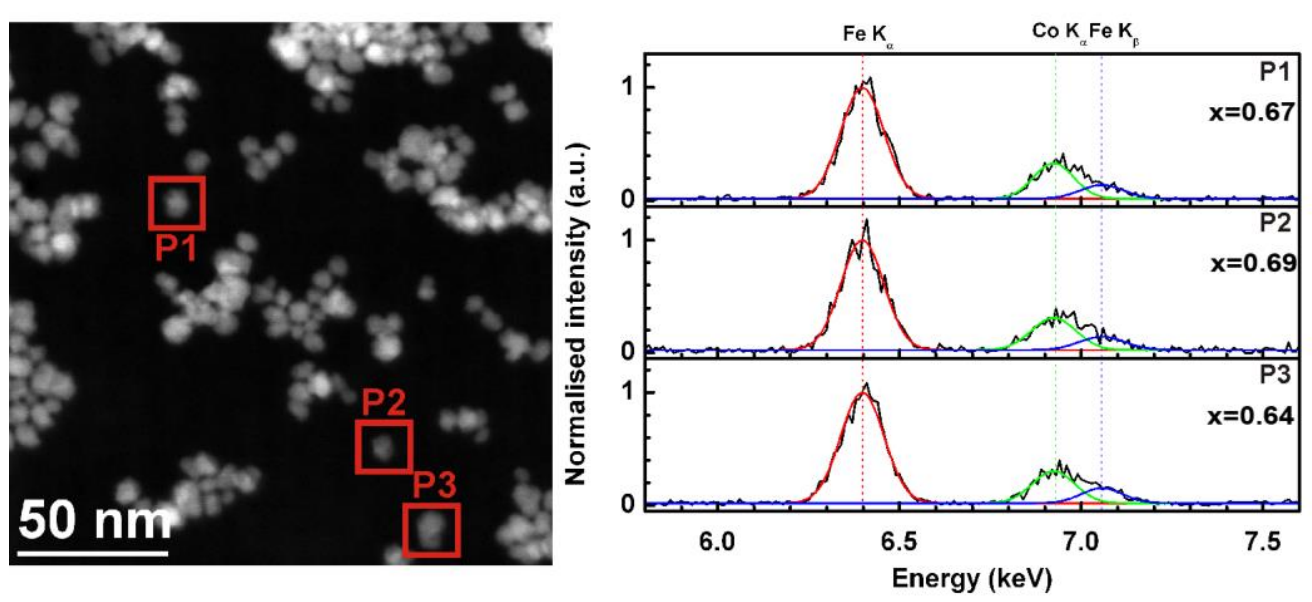

(B)
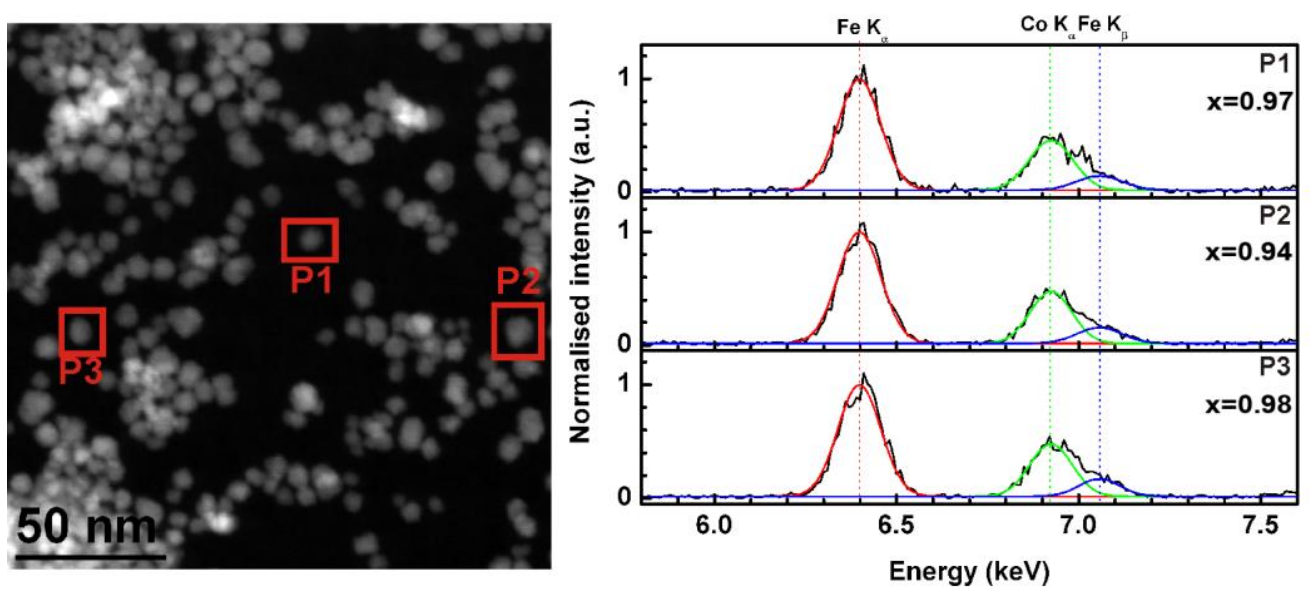

(C)

Figure 2 

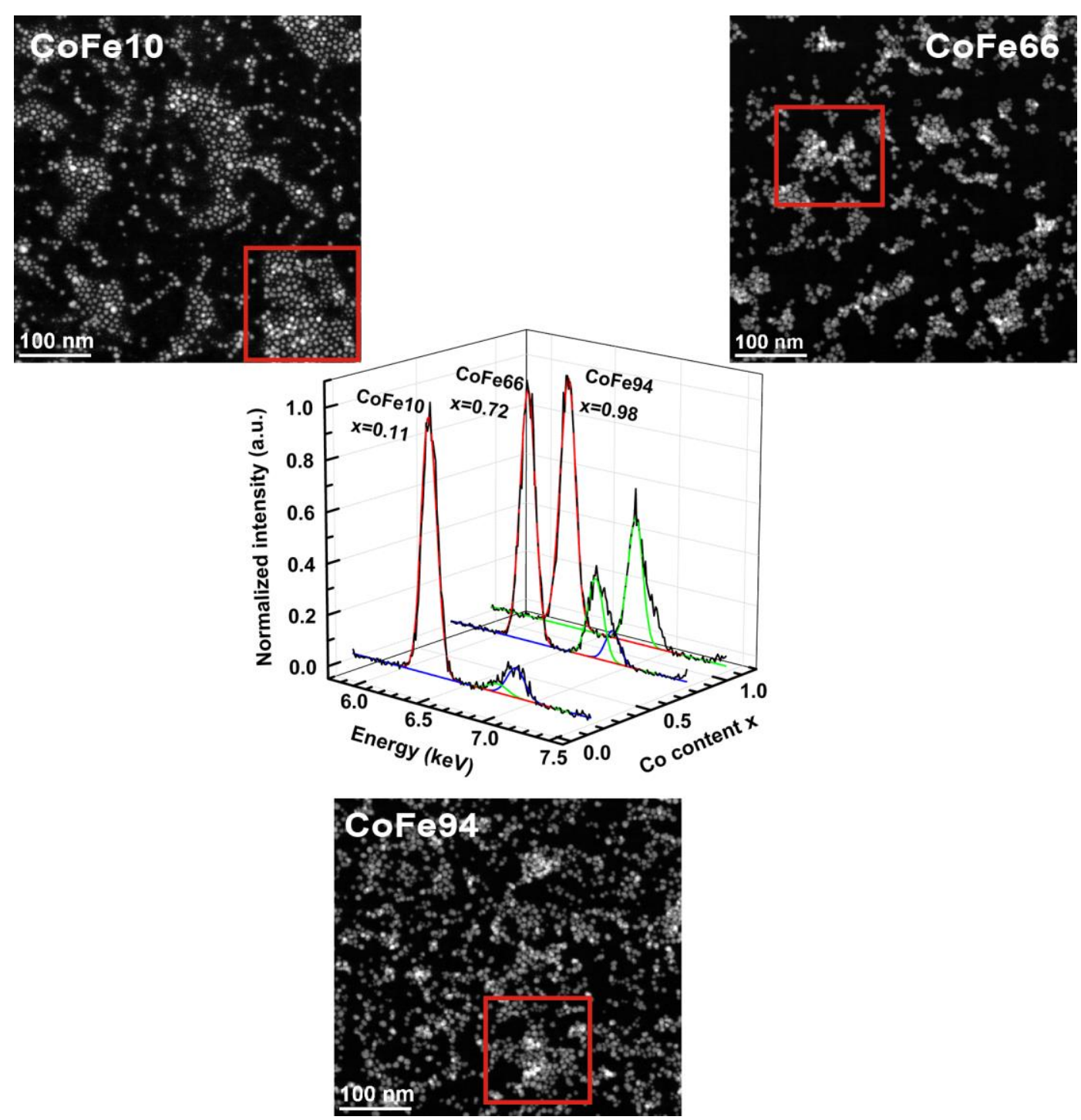

Figure 3. 

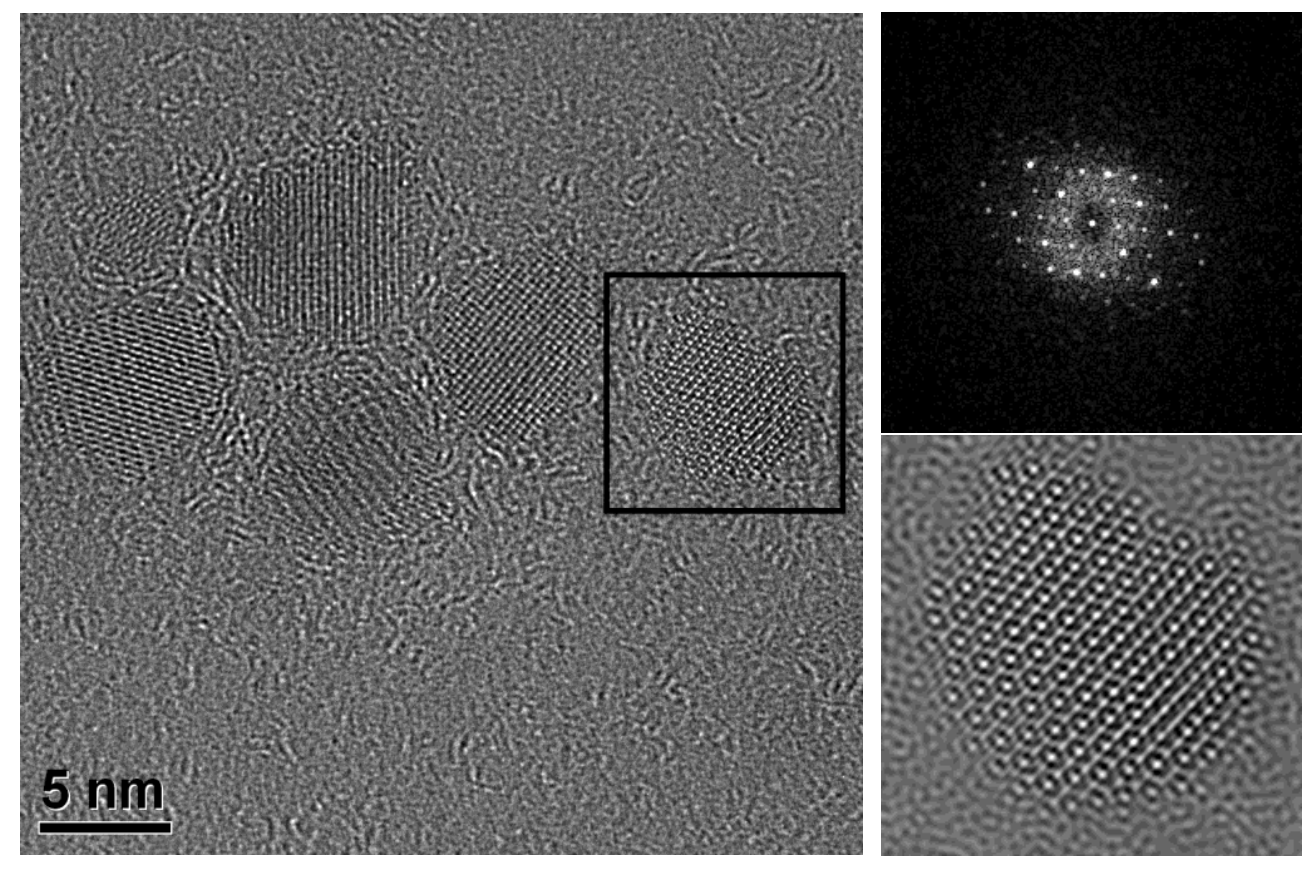

(A)
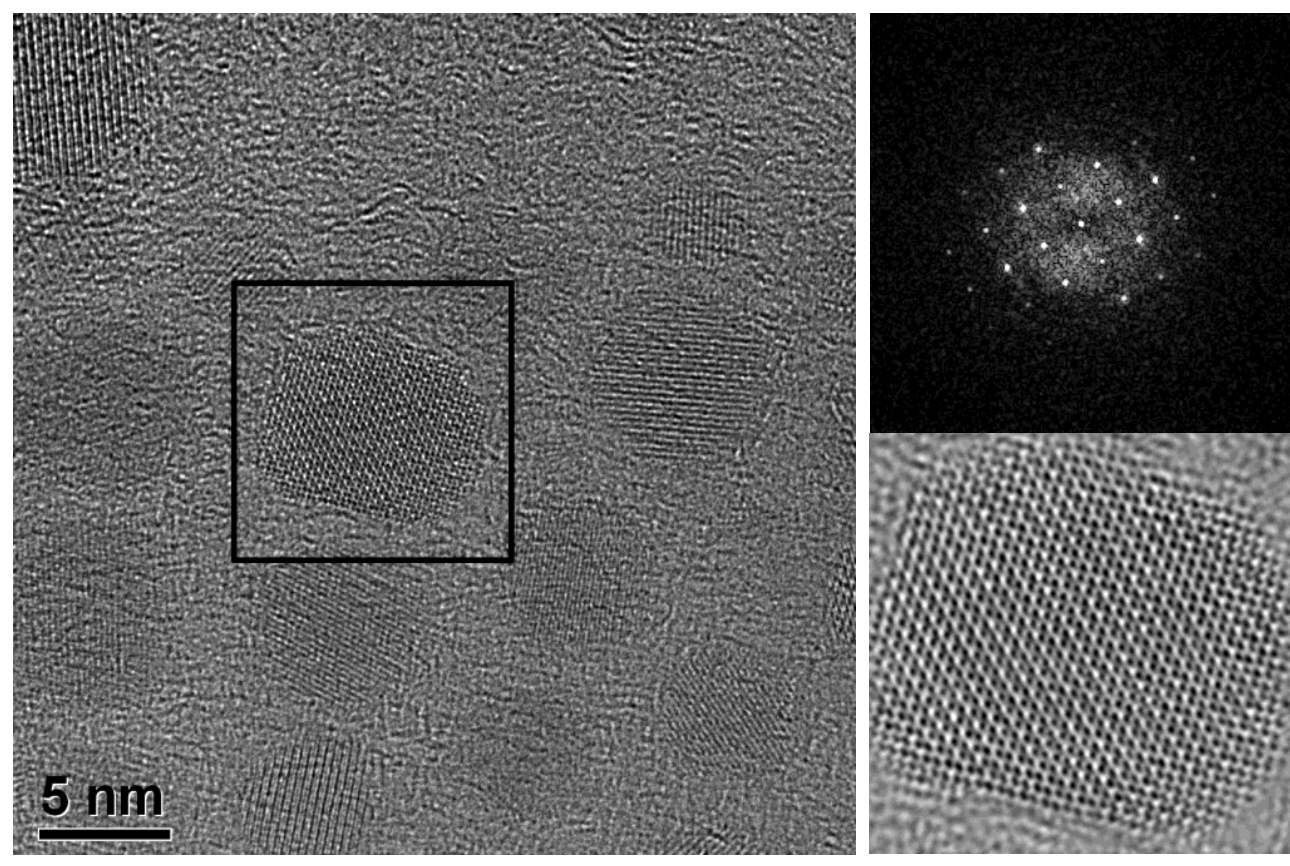

(B)

Figure 4. 

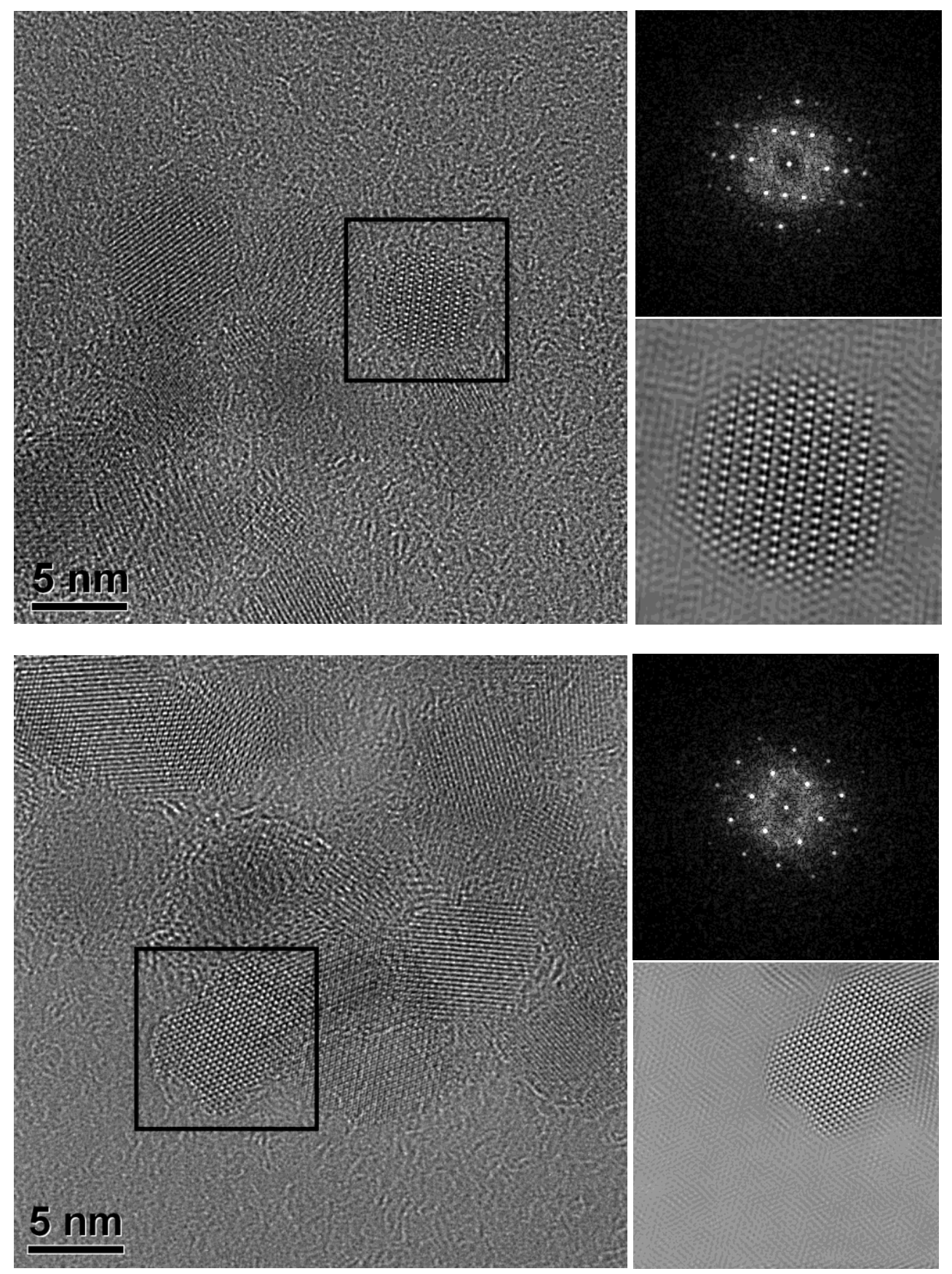

Figure 5. 

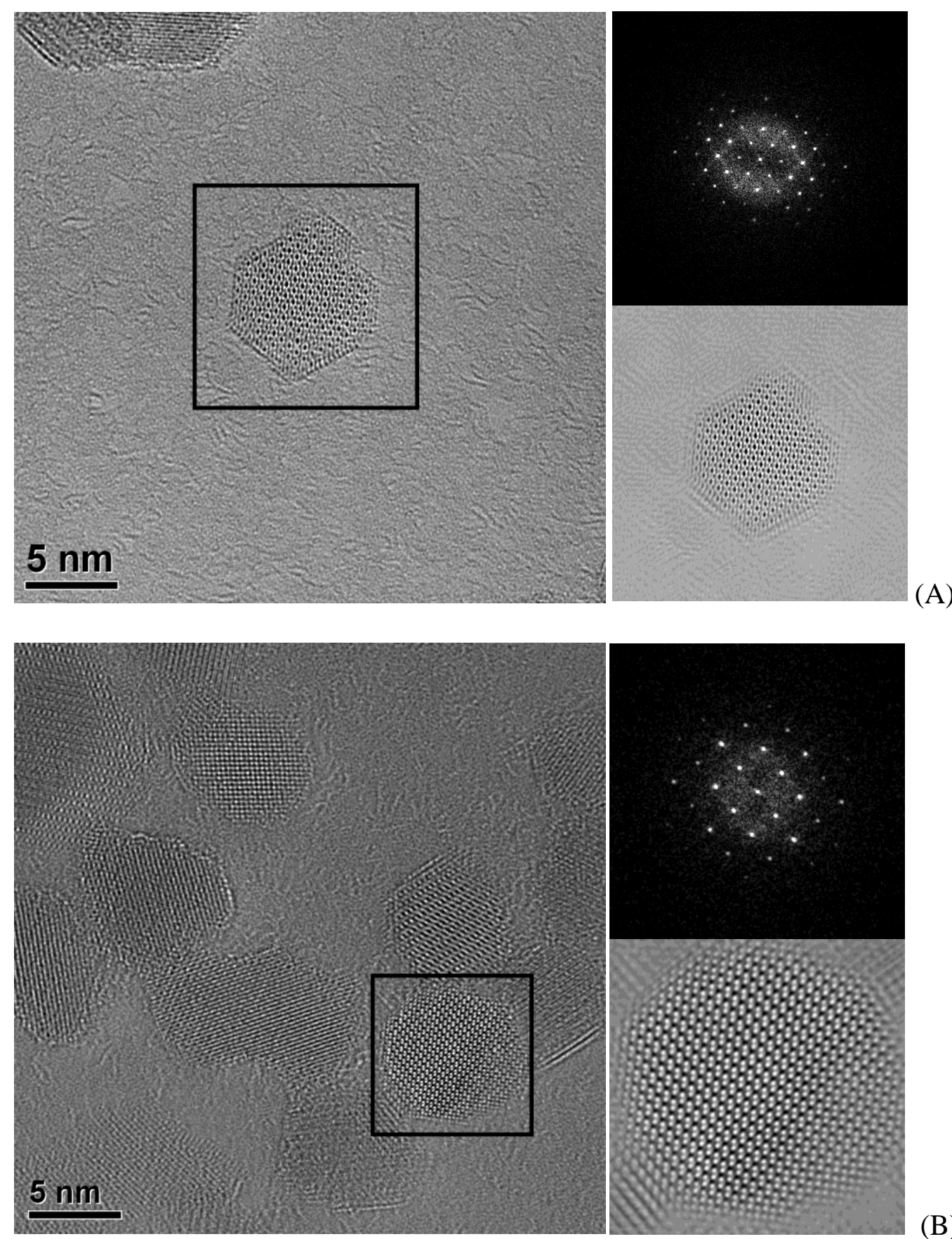

(B)

Figure 6. 
Figure 7.

Figure 8.

Figure 9. 